\title{
La Poesía Peruana en 1940
}

\begin{abstract}
A NO ha sido 1940 de solaz poético para el gran público peruano, más que de satisfacción para los grupos selectos. Con decir que en su trascurso se han desarrollado y cumplido dos convocatorias para juegos florales, parece haberse expresado lo suficiente. Los concursos poéticos tuvieron lugar en Cuzco, con ocasión de la fecha conmemorativa del Inca Garcilaso de la Vega, y luego en Lima, con motivo de la fiesta de primavera, ardorosamente festejada por la juventud universitaria. De ambas competencias intelectuales, no obstante que la segunda tuvo lugar en Lima, han salido premiados valores provincianos como los poetas Nieto y Garrido. No falta, por ello, quien afirma que la capital está perdiendo por ahora su calidad de centro intelectual del país, que antes mantuvo tan enhiestamente, y que hoy la inquietud cultural cunde triunfalmente por doquiera en otras latitudes del territorio nacional. Lo cierto es que la producción intelectual se descentraliza progresivamente, por lo menos en forma parcial en estos últimos años.
\end{abstract}

Los Juegos Florales de Cuzco han consagrado a un recio poeta cuzqueño. Luis Nieto, triunfador con un "Romance cholo por el Inca Garcilaso de la Vega", que revela una auténtica sensibilidad, un discreto sentido de la forma, aunque no exento de influencias garcialorquianas. Mayor originalidad demuestra un bellísimo poema suyo, compuesto con la misma ocasión: "Elogio de Luz Marina".

Los poemas mencionados constituyen, sin duda, los mejores aportes que contiene la Antología poética del Cuzco (Editorial Rozas, Cuzco, 1940), editada para dar a conocer las composiciones presentadas a los Juegos Florales, por el "Centro Inka Garcilaso" de esa ciudad. En realidad, a pesar del membrete, no se trata de una 
antología, pues de tal no tiene sino el título, notoriamente excesivo para una simple recolección de composiciones concursantes, sin base de selección alguna y sin punto de vista crítico. Pues una antología no es únicamente la recopilación de poesías dispersas de muchos autores, sino una selección que debe responder a determinados criterios previamente establecidos y a una pauta de cuidadosa distribución de autores y de creaciones, a más de la cuidada transcripción de datos bio-bibliográficos. Constituiría en verdad poca gloria para las letras cuzqueñas el contenido del folleto con tan presuntuoso título -que puede inducir a erróneas y desfavorables apreciaciones-, ya que existen, sin duda, en dicha región del Perú, muestras más estimables de poesía de ahora y de antes que las pocas y en general mediocres composiciones compiladas.

Los Juegos Florales de Lima, convocados por el Centro Federado de Derecho de la Universidad Mayor de San Marcos, revelaron a un poeta de no escasos méritos: Julio Garrido Malaver. La circunstancia de haber participado nosotros como miembros del Jurado de Poesía en dicho concurso, nos brindó ya ocasión de manifestar nuestro juicio en el fallo emitido. Garrido se ha revelado, con su "Canto a la primavera en varios momentos" y otro simple "Canto a la primavera", que alcanzaron premios, así como con sus trabajos en prosa, también laureados, como autor de singulares posibilidades para lo futuro. Fuera lástima que estos premios circunstanciales alteraran su modestia y su espiritu de superación, pues en él anida una singular capacidad para dominar tanto la poesía como la prosa, y en planos diversos. Se echa de ver que Garrido no se ha encontrado aún, y por eso hay que hacer votos para que prosiga en la tarea intelectual, alimentando cada día su aptitud de creación realmente original y promisora. Su primer libro de poesías y prosas poemáticas, titulado Vida de pueblo (Ed. Lascano, Lima, 1940), así nos lo confirma.

Las recientes "Ediciones Baluarte" han lanzado durante el año dos libros de poesía: Gualda y rosicler, de Augusto Mateu Cueva, y Kollasuyu, de Emilio Vásquez.

Emilio Vásquez renueva en este libro la modalidad expresionista ya estudiada por nosotros en otras páginas. Sus nuevos poemas dejan advertir que el poeta ha ganado en robustez - pese a cierto eco de Alejandro Peralta en la composición "Tarde andina"-, en vitalidad 
y en dominio formal, alejándose progresivamente del estridentismo al uso en época ya periclitada. Su madurez notable, su empeño entusiasta, la voz tajante de su poesía y su sensibilidad para la captación del paisaje y para recoger la emoción del habitante del altiplano hosco y del valle florido, lo confirman como uno de nuestros valores más estimables dentro de su tendencia.

La tendencia purista ha tenido cultivadores igualmente escasos, pero interesantes. Un juvenil y eficiente aporte lo constituye Estación para florecer (Pacasmayo, 1940), de Carlos Alfonso Ríos, alma de poeta verdadero, prometedora de insigne producción. José Varallanos, de generación anterior a la de Ríos, y que antes había logrado consagración en otras modaliđades poéticas, demuestra, con su nueva obra Elegía en el mundo (Huancayo, 1940), la variedad de tono en su emoción artística, su inquietud inmensa e indoblegable y un certero dón para conseguir la expresión sugestiva de la imagen.

A generación intermedia entre la de Ríos y la de Varallanos pertenece Carlos Cueto Fernandini, vocación auténtica de estudioso $\mathrm{y}$ artista de verdad y sin alardes. Esta vez ha lanzado su primer poemario, el cual hace percibir, sin duda, la voz más pura y original de la nueva poesía en el año transcurrido. Poemas dispersos, aparecido en separata de la revista 3 , confirman la existencia de un temperamento ya definido en finos matices de expresión y bello acierto de imágenes. Pocas veces se cumplen en un libro inicial como éste los calores de lo primigenio y de lo maduro, porque Cueto ha conseguido en pocas páginas revelar méritos que pocos logran demostrar en gruesos volúmenes.

El empeño de los directores de la revista 3 ha permitido que este año aparezcan en sus "Cuadernos de cocodrilo" los poemas dispersos de Cueto, y que, aparte de los Poemas de César Atahualpa Rodriguez y el "Canto a Sachaca" de Guillermo Mercado, no rigurosamente inéditos, fuera lanzado Florecimiento animado, un nuevo libro de Mario Florián, perteneciente a los grupos más jóvenes. Florián se desliga esta vez del purismo, ensayando acertadamente el neo-impresionismo. Es muy interesante esta muestra reveladora de su aptitud para objetivar la nota poética, con intenso acento lírico. $\mathrm{Y}$ es por demás satisfactorio que no acuse una poesía de esta índole la frecuente vecindad de forma y tono que muestran los poetas de tal tipo con la obra de García Lorca y otros españoles recientes. 
No se ha librado de ella ni Luis Nieto, el poeta laureado de Cuzco, ni José Torres de Vidaurre, de quien ha aparecido la tercera edición de su Romancero criollo (Lima, Lib. e Imp. Miranda, 1940), tan estimable por otros conceptos, ni tampoco Nicanor A. de la Fuente, que ha dado a la publicidad La feria de los romances (Imp. Bracamonte, Chiclayo, 1940). Tanto Torres de Vidaurre como De la Fuente se sitúan en el mismo plano de amena y pintoresca exploración del alma popular de la costa peruana, tan llena de originalidad y fuente de armonia y gracia espontáneas. Ambos autores han rastreado con singular buen éxito en la parla y la anécdota populares y han fijado en términos definitivos muchas expresiones y relatos que estaban destinados a perderse o desvirtuarse. Nicanor de la Fuente acusa, además, su apartamiento oportuno de cierta poesía dislocada y estridentista ya inactual, de la cual fué muestrario poco acertado su libro anterior, extemporáneo e intrascendente. Los romances últimos, en cambio, nos confirman la evolución eficaz y plausible de su fino temperamento.

Otros dos libros afines cierran este recuento. Se trata de Senderos (Ed, Los Nuevos, Lima, 1940), de Víctor H. Tauro, y Hontanares (Santiago de Chile, 1940), de Graciela del Campo y Plata. Por lo que demuestran de inquietud juvenil el primero y de consagración al culto de las bellas formas el segundo, ambos son estimables dentro del corte romántico que los caracteriza. Parecen hermanarse asi el impulso de la adolescencia con la visión sentimental de las cosas, pasadas por el tamiz de cierto idealismo esteticista de mediados del siglo anterior.

No podria terminarse este balance de la producción poética de 1940 sin considerar dos ediciones mexicanas sobresalientes, en cuanto a su presentación y a su significado, de obras de grandes poetas peruanos ya fallecidos: César Vallejo y Manuel GonzálezPrada.

Al poeta español Juan Larrea, avecindado una época en tierras peruanas y muy vinculado a los movimientos renovadores de postguerra en el Perú, se debe la edición completa y definitiva de la obra póstuma de Vallejo titulada España, aparta de mí este cáliz (Ed. Séneca, Col. Lucero, México, D. F., 1940), cuyos quince poemas nos eran sólo conocidos fragmentariamente. Larrea agrega a la edición un prólogo suyo lleno de calor vital y de comprensión 
latente por la obra del gran poeta peruano, precisando los alcances, el significado profundo y la trascendencia de estas composiciones cuando ya la muerte rondaba en torno de Vallejo.

Carlos Garcia-Prada, profesor de la Universidad de Washington, reputado crítico de Colombia $y$ autor de una interesantísima Antología de líricos colombianos, ha dado a la publicidad la Antología poética de don Manuel González-Prada (Ed. Cultura, México, D. F., 1940), patrocinada por el Instituto Internacional de Literatura Iberoamericana, que inicia con este volumen una Biblioteca de Clásicos de América. Este libro es muy revelador de la estimación universal de la obra poética de González-Prada, tan bien justipreciada antes por el gran espíritu de Federico de Onís en su Antología de la poesia española e hispanoamericana. Constituye un homenaje intelectual al Perú el hecho de empezar una colección de la importancia de CLÁsICOS DE AMÉRICA con la antologia poética del escritor peruano. García-Prada ha realizado con verdadera conciencia de su tarea un aporte perdurable al estudio de las letras iberoamericanas, $y$, asi, en la Introducción que precede a las composiciones recopiladas, traza un concienzudo estudio de conjunto de la poesía de González-Prada, a través de sus serias y perspicaces innovaciones métricas y estróficas. Obras como la comentada, que unen a la seriedad de la investigación el propósito de divulgación universal de los valores más sólidos de América, merecen el estímulo y el aplauso más sincero, ya que contribuyen a definir la fisonomía cultural americana.

Juzgándolo en su conjunto, 1940 parece ser año, en materia poética, de promesas, de perspectivas halagüeñas, más que de realizaciones: año de concursos felices aunque, como todos los concursos, sujetos a la relatividad de la consagración y a la circunstancialidad de la misma; año de reediciones bien acogidas y de apreciables intentos juveniles; año de antologías y de ediciones bellísimas de poetas esclarecidos. No irrumpen, en cambio, los valores definitivos ni se consagran generaciones.

Estuardo Núñ̃z, Lima. 
